\title{
Fatigue crack propagation in turbine disks of EI698 superalloy
}

\author{
A.A. Shanyavskiy \\ State Centre for Civil Aviation Flights Safety, Airport Sheremetievo-1, PO Box 54, Moscow region, Chimkinskiy State, \\ 141426, Russia \\ shananta@mailfrom.ru
}

\begin{abstract}
In-service fatigue cracking of turbine disks of EI698 superalloy is discussed based on crack growth analyses. In the bolt joint for disks to shaft connecting there is high level of stress-state, which directed to earlier in-disks fatigue crack origination in low-cycle-fatigue regime. Fracture surface pattern such as fatigue striations were used for their spacing measurement and crack growth duration estimating. Developed disk tests on a special bench by the equivalent program to in-service cyclic loads have allowed discovering one-to-one correlation between fatigue striation spacing and crack increment in one flight. Number of fatigue striations and beach-marks calculations permitted to estimate crack growth period for the different stages of in-service disks cracking. Equivalent stress level for in-service cracked disks was calculated and compared with stress-level intested disks under stress equivalent program to in-service operated cyclic loads. Based on this result nondestructive inspection intervals were discussed and recommended for in-service disks in dependence on number of their flights at the moment of developed inspection to exclude in-flight disks fast fracture.
\end{abstract}

KEYwORDS. Nickel-based superalloy; Crack initiation; Crystallographic facet; Fatigue striations; Crack growth period; Stress equivalent; Non-destructive inspection.

\section{INTRODUCTION}

A ircraft structures in-service fatigue cracking can be appeared under wide range of cyclic loads combinations [1-4]. Because of difference in structures loading conditions from one flight to another it can be effective to use material reaction for describing damage in-time accumulation in each of them [5]. This reaction on the external loading can be considered as material property pre-venting crack occurring and growth. Discussed property has not only mechanical but physical sense, and in the case of aircraft structure fatigue cracking, when Mode I crack opening is dominant, the discussed process can be described, for instance, applicably to durability, based on bifurcation diagram [6,7], Fig.1.

The bifurcation diagram allows describing fatigued metals behavior based on uniform synergetical methodological principle applicably to systems which evolution occurs far from the equilibrium position. Stated the synergetics concept allows to connect among themselves all experimentally demonstrated data on research of metals fatigue at different scale levels and to explain increase and decrease of dispersion of fatigue durability in process of increase of cyclic stress level at achievement of critical stress levels. Such manner of metal fatigue behavior consideration is lawful, even if in process of evolution metal undergoes only one unstable condition and consequently has only one bifurcation area between two boundary conditions when it is not loaded (one border) and when it is completely failed (the second border).

Because of complicated external cyclic loading and environment deterioration, material re-action there has to be considered based on the stress equivalent value which has difference in dependence on a structure and its stress-state [8]. In the case of through or semi-elliptically-shaped cracks, which usually takes place on the first stage of structure cracking one can see simply equation for principle stresses $\sigma_{1}, \sigma_{2}$, their ratio $\lambda=\sigma_{2} / \sigma_{1}$, and value of $\sigma_{e}$ in the form [9]: 


$$
\sigma_{e}=\sigma_{1}\left(1+A_{1} \lambda+A_{2} \lambda^{2}\right)
$$
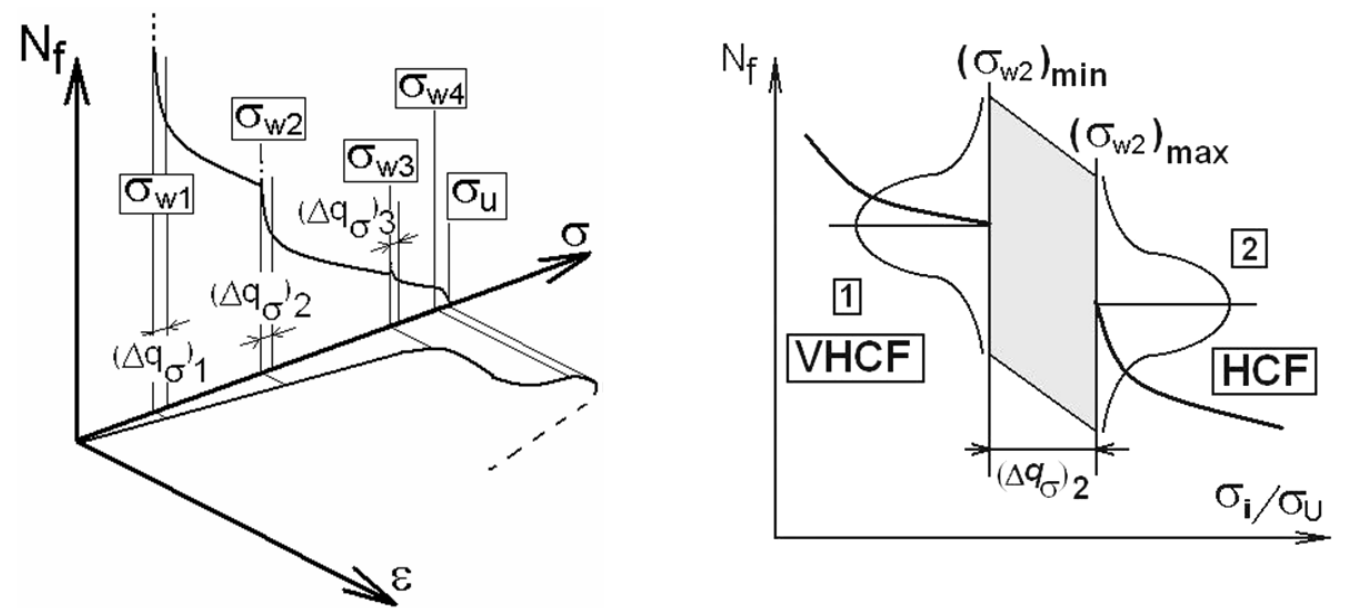

Figure 1: The bifurcation (a) diagram of metals fatigue has constructed according to the tension diagram and (b) schema of probability of metals cracking variation for the bifurcation area $\left(\Delta q_{\sigma 2}\right)$. Bifurcation areas are specified at transitions from nano- $\left(\sigma_{\mathrm{w} 1}-\sigma_{\mathrm{w} 2}\right)$ to meso$\left(\sigma_{\mathrm{w} 2}-\sigma_{\mathrm{w} 3}\right)$, and macro- $\left(\sigma_{\mathrm{w} 3}-\sigma_{\mathrm{w} 4}\right)$ scale level of metals fracture.

Parameters $A_{1}, A_{2}$ depended on the material-type and can be determined in specimen biaxial tests [9].

Applicably to in-service aircrafts, in the case of Low-Cycle- (LCF) and High-Cycle-Fatigue (HCF), material reaction can be discovered after crack occurring when fracture surface will be analyzed in electron microscope [4]. That is why, if there were not estimated in-tests parameters of Eq.1, fractographic analyses of cracked aircraft structures can be used for estimating $\sigma_{e}$-value because fatigue striations and $\Delta K_{e f f}$ or $K_{e}$ - equivalent value has unified correlation in term of material reaction independently on the in-service unknown external loading condition [4-6].

Possessing aviation gas-turbine engines (GTE) with higher in-service parameters and reduced weight required heavier thermal and mechanical tension of the engine parts, including the turbine disks. Gas-turbine engines of some types have the turbine disks designed in such a way (existence of the central hole, arrangement of the fastening holes in the stressed part of the hub) that the disk material of nickel-based superalloy EI698 experiences elastic-plastic loading in stressconcentration zones by the holes. There is clear material biaxial stress-state in areas of crack origination and propagation with different $\lambda$-ratio for different bolt joint stressing from one exemplar of turbine disk to another.

Besides, the working temperatures are quite moderate in the fastening-hole regions. Hence, creep effects do not contribute much here and so the low-cycle fatigue in these regions is mostly responsible for the disks lifetime.

Under LCF conditions, the crack-growth period occupies most of a material lifetime [4]. Therefore, stronger thermal-andmechanical tension of the disk material together with possible material defects introduced in manufacturing and in periodic servicing of the engine reasons the damage-tolerance approach to the disk service.

In service, fatigue cracks were found to grow in Stage-III disks of NK8-2u engine, Tu-154B aircraft; the cracks grew in the sites of high stress concentration by the holes used to fasten disks to the engine shaft. Complicated stressed state was calculated with finite-element method for those disk sites where linear stressed state was expected to exist according to the traditional calculation techniques $[10,11]$. Solutions based on the generalized concept of plane-stress state in a series of sections neglect tangential stresses and, partly, a three-dimensional stressed state of the disk rim, including its labyrinthseal portion. Erroneous estimations of the real stressed state are even more likely when applied to the stress-concentration sites by the holes for bolted joints of a turbine disk and shaft. In service, it is by those holes that fatigue cracks arise to then propagate towards the hub and shaft. The actual stressed state differed from the calculated one: according to calculation, the greatest stress intensity would correspond to the section normal to the plane actual crack growth.

Stage-III turbine disks of two NK8-2u engines (labeled arbitrarily as P-1 and P-2) broke in service. One of the in-service failed turbine disks has shown in Fig. 2. Both disks broke in a similar way during a starting run along the takeoff runway. Hence, a reasonable guess was that the same cause brought these similar-stage turbine disks about the failure.

Moreover, when having the engines serviced after different operation times, numerous fatigue cracks were discovered in the bolt-joint holes of the disks. Therefore, disks with different numbers of cracks in the holes were selected after different operation times, aimed at the analysis into the trends of the crack initiation and propagation. 


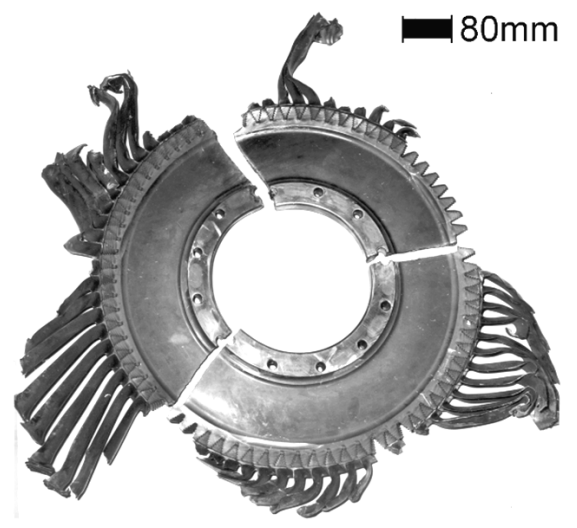

(a)

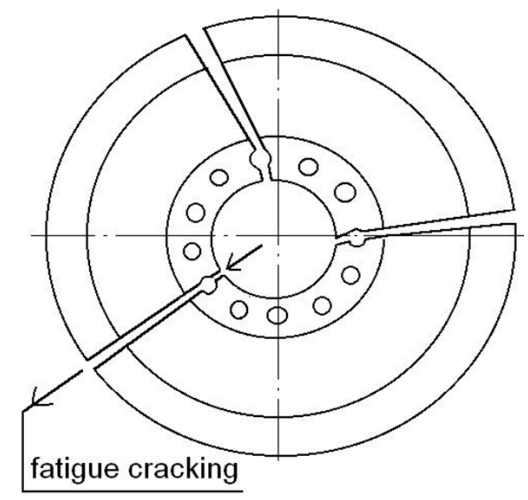

(b)

Figure 2: (a) General view of the Stage-III turbine disk of a NK8-2u engine; (b) Scheme of the disk cracking sequence. Arrows indicate the disk section in that initial fatigue crack propagated.

\section{INVESTIGATION PROCEDURE}

I Material

T t was well-known superalloy EI698 is strengthened primarily by precipitation of a gamma prime phase ( $\left.\gamma^{\prime}\right)$, Fig. 3. The grain size was measured using the line intercept method on optical micrographs. The distribution of grain size has shown that the mean grain size, excluding the presence of annealing twins, is about $38 \mu \mathrm{m}$. Large grains on the order of two to three times of the average grain size and large grain clusters exist in the microstructure.

The disk material_EI698 superalloy_-was tested using standard test specimens. The latter were made from the disks, broken in service, and subjected to shirt-term tensile tests and impact-toughness tests at $20^{\circ} \mathrm{C}$ and to creep-rupture tests at $750^{\circ} \mathrm{C}$ with $420 \mathrm{MPa}$ applied stress (smooth specimens), $650^{\circ} \mathrm{C}, 720 \mathrm{MPa}$ applied stress (smooth specimens) and $650^{\circ} \mathrm{C}$, $850 \mathrm{MPa}$ applied stress (notched specimens with a $0.15-\mathrm{mm}$ curvature radius of the notch tip). The specimens were cut out of the under-rim part of a disk along a chord direction and out of the hub part.

At $20^{\circ} \mathrm{C}$ both disks exhibited mechanical properties that satisfied all standard requirements to the new disks. Ultimate tension stress, Yield stress and elongation were respectively not less than $1150 \mathrm{MPa}, 720 \mathrm{MPa}$ and $19 \%$.

The time to fracture shown by the smooth and notched specimens tested for creep-rupture strength appeared well above the smallest standard one (not below 50 hours), i.e., was indicative of a quite good high-temperature strength of the disk material.

Metallographic investigation of both investigated disks in area of crack origination has shown material structure in accordance with certificate for manufactured turbine disks (see Fig. 3) without any evidence of faults.

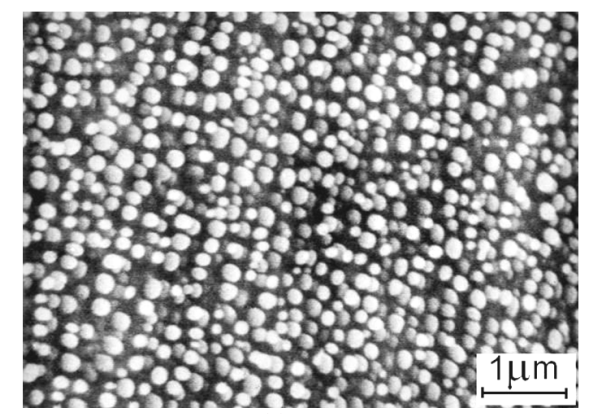

(a)

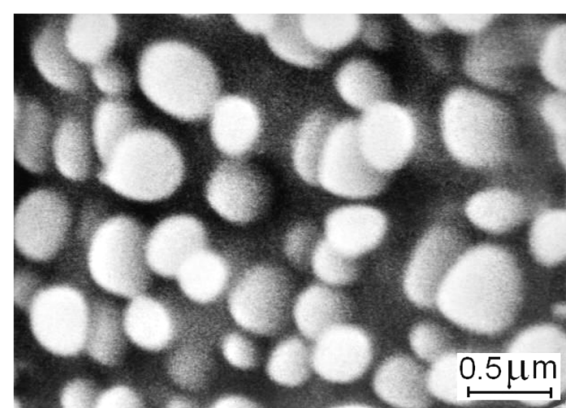

(b)

Figure 3: Typical microstructure of EI698 with gamma prime phase $\left(\gamma^{\prime}\right)$ under (a), (b) different magnification in electron microscope.

\section{Non-destructive inspection data}

In-service, after the failure discovering of two turbine disks, there was performed non-destructive inspection of all operated turbine disks. In many cases there were discovered cracks being different in size for different disks. Disks with 
cracks were removed and some of them used in the present investigation. The disks with cracks that were selected for their fracture surfaces investigation and failed disks are described in Tab. 1.

\section{Test procedure}

Two of in-service cracked disks with small cracks were not subjected to crack opening and selected for their testing on the special bench-test. It was reproduced in-service acting stress-state with maximum stress level in accordance with maximum disks rotation speed in flight. During fatigue tests, in disks crack propagation was registered by the nondestructive day-penetrate periodical inspections.

\begin{tabular}{|c|c|c|c|c|c|}
\hline №№ & $\begin{array}{l}\text { Time since new, } \\
\text { flights/hours }\end{array}$ & $\mathrm{n}_{1}$ & $\mathrm{n}_{2}$ & $\mathrm{c}_{\mathrm{i}}, \mathrm{mm}$ & Comments \\
\hline 1 & $1329 / 3097$ & 11 & 18 & $0.2-1.05$ & In-service discovered crack \\
\hline 2 & $1335 / 3658$ & 8 & 9 & 1.5 & $-{ }^{\prime}{ }^{\prime}-$ \\
\hline 3 & $1421 / 3962$ & 11 & 8 & $0.05-1.65$ & $-{ }^{\prime}{ }^{-}-$ \\
\hline 4 & $1499 / 3733$ & 1 & 8 & 2.0 & $-{ }^{\prime}{ }^{\prime}-$ \\
\hline 5 & $1690 / 5780$ & 11 & 2 & 0.6 & $-{ }^{\prime}{ }^{\prime}-$ \\
\hline 6 & $2049 / 4688$ & 4 & 13 & $0.1-0.5$ & $-{ }^{\prime}{ }^{-}-$ \\
\hline 7 & $3121 / 6609$ & 12 & 9 & 1.2 & $-{ }^{\prime}{ }^{-}-$ \\
\hline 8 & $\begin{array}{c}2048 / 5994+ \\
561 / 2000 \text { bench runs }\end{array}$ & 8 & 1 & 4.0 & $\begin{array}{l}\text { In-service discovered crack; } \\
\text { bench tests added }\end{array}$ \\
\hline 9 & $\begin{array}{c}3079 / 5990+36 \\
\text { programmed runs }\end{array}$ & 12 & 12 & 2.8 & - “ \\
\hline 10 & $2619 / 6345$ & - & - & - & Broken in service \\
\hline 11 & $2696 / 5382$ & - & - & - & Broken in service \\
\hline
\end{tabular}

Table 1: In-service operation time of NK8-2u engines, numbers $n_{1}$ of the holes (see schema of the Fig.1) with cracks and $n_{2}$ of cracks in holes and crack size as measured by the hole-surfaces.

In one disks (P-3), it was realized block of 42 cyclic loads, reflecting in-service operated stress range during engine working, with constant stress amplitude and R-ratio near 0.4 between two neighbored disks cycling with one cycle at $\mathrm{R}=0$. There were reproduced 50 blocks in disks fatigue tests. Maximum of stress level was reproduced for in-flight operated engine.

In another disk (P-4), it was used engine with reproducing for disk in-service loading by the cyclically-equivalent-program (CEP). This program used for estimating design service goal for in-service disks [12, 13].

\section{Fractographic analyses}

All selected disks were subjected to fractographic investigation on the scanning electron microscope EVO40 of the Karl Zeiss Company. Fracture surface patterns were used to reproduce in-service crack propagation in number of flights based on fatigue striations or beach mark number in accordance with developed earlier methodology [4, 6].

\section{INVESTIGATION RESULTS}

\section{General trends of crack growth revealed by the broken disks}

$\mathrm{P}$ -1 disk broke in service by cracking in three radial sections arranged at $120^{\circ}$ angles to one another (see Fig. 2). These sections passed holes through that the disk was bolted to the engine shaft. In P-2 disk these angles were $150^{\circ}, 120^{\circ}$, and $90^{\circ}$. Having matched the disk fracture surfaces, we saw the fracture to first initiate in one radial 
section of a disk. As the crack propagated, plastic deformation of the disk occurred to cause a 35-mm crack-opening displacement, next to which final fracture occurred over the two different radial sections.

Finding the material to fit assigned mechanical properties indicated that the LCF cracks developed in the discs stressed as high as to exceed their working capacity. Therefore, the problem arose to make use of the actual durability with the still impossible failure of the disk due to the growth of LCF cracks. In fact, this was the problem of running engines with the disks tolerably damaged. We solved successfully this problem owing to the complex investigations that included quantitative fractography as a way of estimating the growth period of fatigue cracks.

We examined visually the fracture surface of the opened cracks to find them initiated in the disk-hub body at the surface of one or several fastening holes on the central-hole side. The cracks propagated along the disk radius toward the central disk hole, Fig. 4. Once a crack grew through, it began to grow toward the disk rim with a danger of disk fracture along its radius. The fractures colored golden formed between the fasting holes, used to bolt the disk to the turbine shaft, and the central disk hole. The fracture morphology indicated that the crack grew transgranularly, typical of superalloys fatigue cracking. Each of the disks had most strongly oxidized zones, arranged closer to the end of the hub. This zone was indicative of quite a long propagation period of the initially non-through semi-elliptic crack (see Fig. 4b).

The web of the disks, broken in service, showed signs of transgranular cracking of a cyclic nature over the region 63 to 65 $\mathrm{mm}$ long between the bolt-joint hole and the rim. These cycles left behind a sequence of fracture zones oxidized to different degrees. Elliptic fatigue lines so-called beach marks (BM) bordered these four zones (see Fig. 4c). Similar trends were revealed by the fracture surface of Stage-I high-pressure-compressor disk, made of titanium alloy VT3-1, in a D-30 engine: here zones of different roughness formed in the disk web [12]. A distance between two neighboring zones (each identified with BM) of different roughness answered to crack propagation during one flight. So in the above turbine-disk case, we considered the whole pattern of crack-propagation from the bolt-joint hole to disk rim as formed during five flights, with the last executive start of the engine in that number.

In both turbine disks, the two remaining fractures were of a mixed type (intergranular plus transgranular) with the signs of macroscopic plastic deformation all over the fracture boundaries; such a fracture pattern is typical of superalloys subjected to short-term static loading.

An important finding was that, in both disks, each of the short-term fractures revealed a portion of fatigue cracking, which, similar to the general long-term fatigue fracture, began by a bolt-joint hole. It was indicative of a multiple fatigue cracking from those holes in both of the in-service failed disks. Those initial portions of fracture were also transgranular and oxidized to golden-gray color. Their semi-elliptic boundary with the area of final shirt-term fracture was distinct, typical of the case that an abrupt increase of applied load occurred as soon as the general fatigue crack grew to its critical size. The general fatigue cracks grew to the dimensions of $2 \mathrm{c}=6.5$ and $2 \mathrm{c}=1.2 \mathrm{~mm}$ at the disk hole surface and $\mathrm{a}=3.0$ and $\mathrm{a}=0.3 \mathrm{~mm}$ in depth direction for the P-1 and P-2 disks, respectively.

The crack grew to sequentially form four fracture zones of respectively changed dominating fracture mechanism that was indicated by the difference in fracture surface patterns.

Zone I (see Fig. 4) reveals gradual growth of the crack from the disk hole, predominantly by forming fatigue striations, Fig. 5. The striation spacing increases along the minor ellipse axis, toward disk-body depth. The smallest striation spacing was 0.5 and $0.3 \mu \mathrm{m}$ for discs P-1 and P-2, respectively. Both values of spacing indicate to low-cycle fatigue conditions of the crack initiation, i.e., to a stress level as high as or higher than the yield strength of the material. A special feature is that the striation spacing increased linearly with crack growth to achieve $1.2 \mu \mathrm{m}$ by the crack-penetration depth of about 1.2 $\mathrm{mm}$, where the second fracture zone began in both broken disks. In the open fractures, striation spacing amounted to 0.7 and $1.2 \mu \mathrm{m}$ for the greatest crack depths of 0.3 and $1.2 \mathrm{~mm}$, respectively. All cracks revealed similar laws of increasing the striation spacing to obviously indicate that both disks experienced an about equally high level of stressed state around the holes.

Designing disks in terms of durability takes into account effect of protractedly holding them mechanically loaded when starting and shutting down the engine. With such holding under LCF-conditions, thermally activated plastic deformation and fracture increase the probability that slowly-going damage of grain boundaries and subboundaries by grain-boundary sliding and vacancy fluxes comes to a completion. Consequently, fracture becomes a mixed type (transgranular plus intergranular) of predominantly intergranular.

The fracture surface revealed fatigue striations to confirm that, with a moderate thermal tension of the disks, the intergranular mode of fracture was suppressed by the transgranular mode and slip. Transgranular slip brings about vigorous cracking of the material and, thereby, hinders from the formation of fatigue striations. Consequently, fatigue striations coexist with cracked regions of the fracture surface.

Zone II of further crack propagation (see Fig. 5) predominantly reveal fracture facets with the steps of intensive transgranular slip and hardly visible dimpled regions. Besides, the dimples look quire shallow. Such an abrupt transition to 
Stage II of crack growth occurs as soon as the fatigue-striation mechanism is suppressed while transgranular slip and grain-boundary sliding become dominating. This is evidence that the fast transgranular slip does not bring about dominating grain-boundary damage of the material.
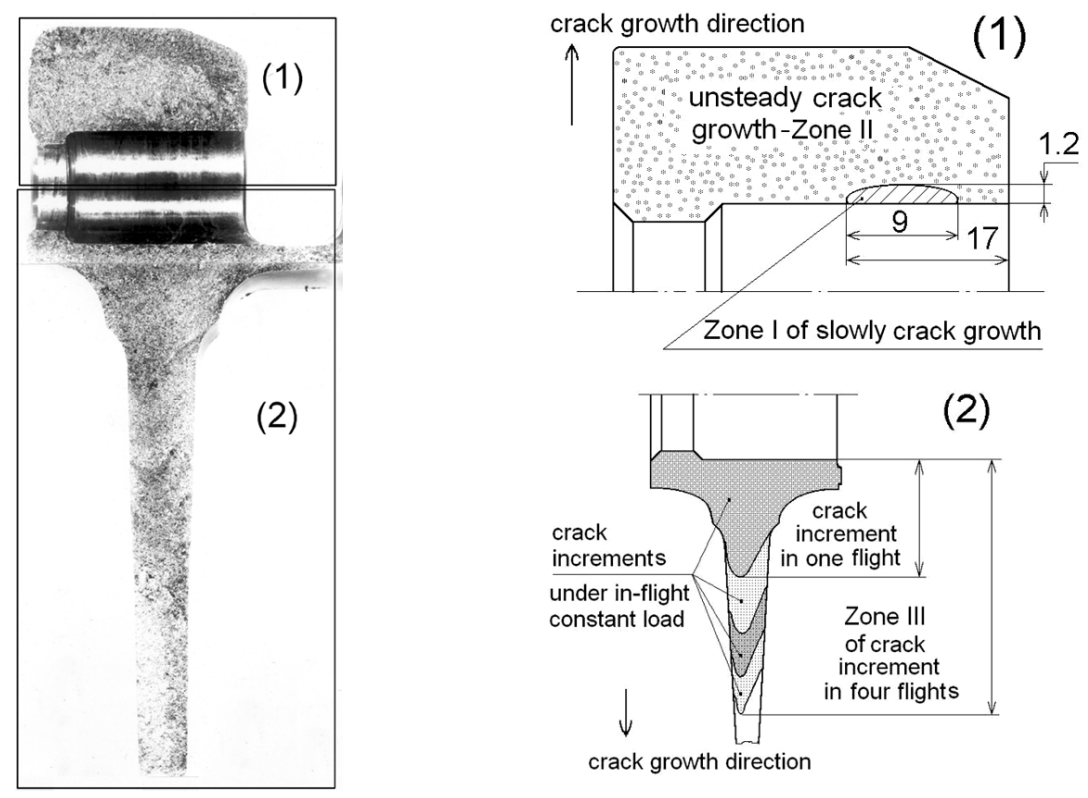

Figure 4: Fracture (general view) in one of the Stage-III turbine discs (NK8-2u engine) has broken in service; (1) and (2) the sequence (schematic) of the crack propagation in a disk.

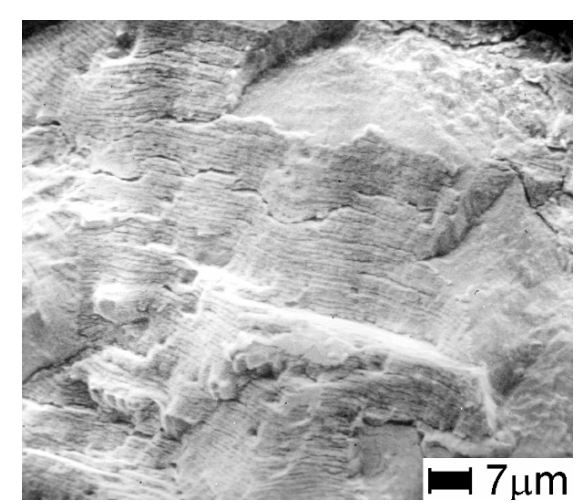

(a)

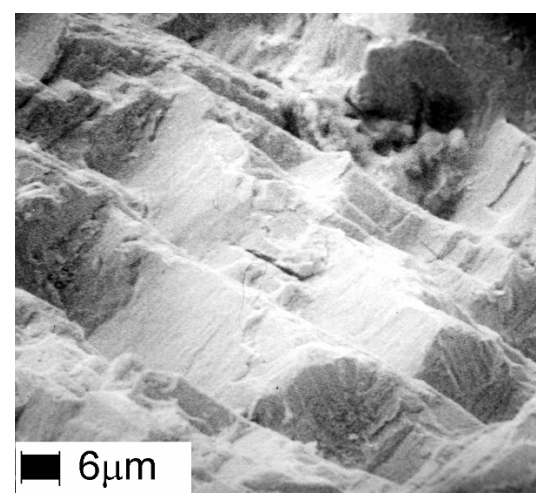

(c)

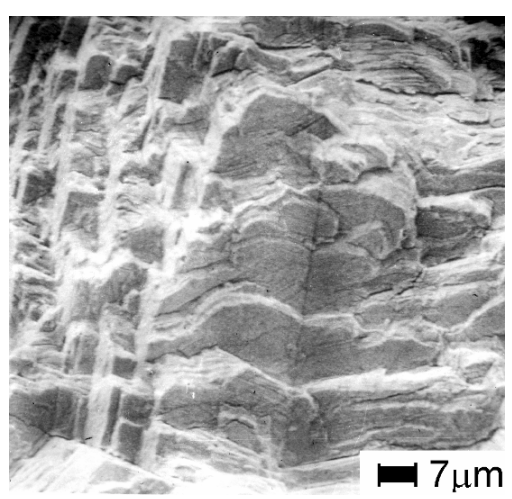

(b)

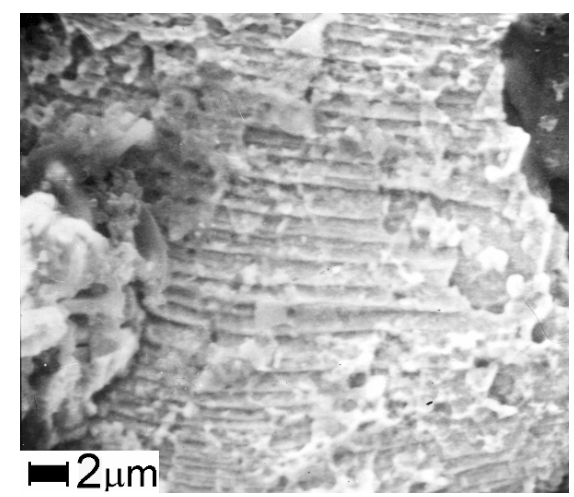

(d)

Figure 5: Fracture morphologies of a in-service fatigued turbine disk (a-c) at the stages of (a) early steady and (b, c) accelerated growth of a fatigue crack and (d) by slow in-flight cracking under repeated static loading (see also Fig. 3). 
If the threshold value of stress-intensity factor $\left(\mathrm{K}_{\max }\right)_{\mathrm{h}}$ is achieved, holding a material mechanically loaded will change a situation at the crack tip as far as the material is sensitive to the loading waveform. Now the plastic zone does not hinder the crack growth in the material held under a constant applied load. The crack grows slowly with progressing mixed transgranular and intergranular slip (see Figs. 5b, 5c). In so doing, the transgranular slip still dominates, indicating that the any serious effect of temperature, known by vigorous formation of grain-boundary voids, does not show itself. Transgranular slip develops until the material ductility is exhausted and, consequently, decohesion on the slip plane occurs the moment that the fracture surface forms. Such a pattern should be associated with the case of a highly stressed material in that transgranular slip occurs easier and, since the material is heated, is not blocked by the grain boundaries. As the slip is finished, cleavage on this slip plane occurs.

The crack propagates from a bolt-joint hole toward the central disk hole in a field of centrifugal forces, which determines the level of long-term static loading of the material. As the crack length increases fast by pure-shear under a constant applied load, we believe that the crack growth is controlled by a slowly increasing stress-intensity factor. These crackpropagation conditions, creative of quite extensive Zone II, are overcritical: the crack propagates fast (by tens or hundreds microns per one flight). Such a behavior of fatigue crack (propagating from the bolt-joint hole toward the engine shaft) conforms to the disk calculations for strength.

Zone III demonstrates a pattern of mixed transgranular fracture. This followed from transgranular slip and static ductile cracking (see Fig. 5d). The visible fracture surface reveals shallow dimples, indicative of low-energy fracture caused by static shear. The grain-body strength becomes virtually exhausted due to preceding vigorous transgranular slip. Consequently, formation of pores is limited as long as the free surface of fracture forms by decohesion on the slip planes. Decohesion appears a dominating way of fracture. Concurrently, local regions experience low-ductility fracture by forming degenerated dimples. Such a pattern is representative of transgranular formation and coalescence of pores, typical of a material held under a permanently applied load, Fig. 6. During a flight long as tens of minutes, a crack can propagate by tens of millimeters. Indeed, Zone-III fractures of the broken disk web reveal five sequentially repeated regions of a changed intensity of the fracture oxidation. These regions correspond to the repeated cycles of heating and cooling of the engine (having it launched and shat down, respectively). The boundaries between the regions conform to the crack-tip profiles the moment that the temperature-and-loading conditions were altered. Each region has extension over 5 mm along the crack path.

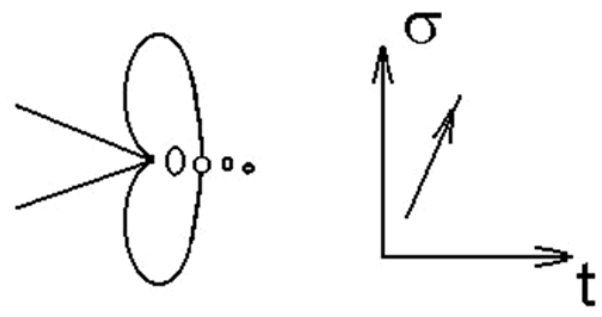

(a)

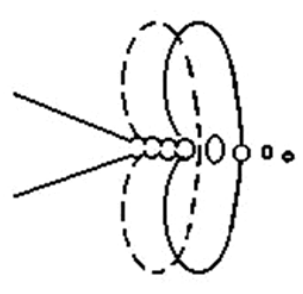

(b)

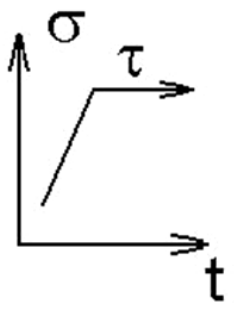

Figure 6: The propagation sequence (schematic) of a fatigue crack under (a) increasing or (b) constant applied load with a result that a dimpled fracture is formed [15].

Zone IV represents the final-fracture area of the disks. It reveals a dimpled-type fracture adjacent to the grain boundaries and characteristic of this alloy when going through short-term fracture under temperature-and-loading conditions reaching its fracture toughness.

Thus, in service, a crack in the disks can pass the propagation Zones III and IV during a small number of flights. The crack propagates here by transgranular slip caused by a constant load applied at the maximum revolutions per minute of the engine. Therefore, the general crack-growth period, primarily contributing to the disk durability, relates to Zone I of the fracture. In Zone I, which extends to $1.0 \ldots 1.2 \mathrm{~mm}$ in depth, steady crack growth occurs according to the fatiguestriation mechanism. Besides, the value striation spacing greater than $0.3 \mu \mathrm{m}$ corresponds to the low-cycle range of fatigue fracture.

The regularities of damage caused by cracks in the disks

We carefully analyzed the above data on the broken disks to compare them with the crack-growth patterns brought to light by disks servicing (see Tab. 1). Therefore, we opened all of the detected cracks and examined them fractographically. 
All of these fractures exhibited fatigue striations with the striation spacing not less than $0.34 \mu \mathrm{m}$ by the edge of the hole, Fig. 7. The crack-growth rate was noticed to increase along the minor axis $a$ (in-depth of a disk hole). This acceleration appeared the smaller the greater operation time to agree with the idea that the periods of a crack initiation and propagation change in the same proportion with a stress level and stressed state of the structure element [4]. In all examined cases, the value of striation spacing grew linearly long the minor axis of the semi-elliptic crack (see Fig. 7). Such a trend is typical of a structure-element behavior in a biaxial stressed state under LCF conditions with a constant strain range [16].

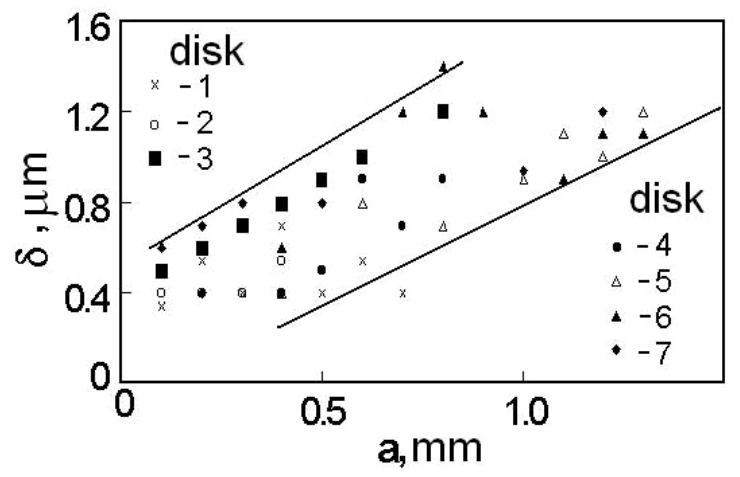

Figure 7: The changing trend of the value $\delta$ of fatigue-striation spacing along the crack-growth direction (minor axis $\boldsymbol{a}$ of the crack front shape) for the group of examined disks (disk data are given in Tab. 1).

Nos. 3 and 4 disks were close to the broken disks as concerns their operation times, and the opened fractures revealed the cracking depths of 1.8 and $2.0 \mathrm{~mm}$, respectively. Deep as $1.2 \mathrm{~mm}$, the value of striation spacing was $1.2 \mu \mathrm{m}$ (close to that in the broken disks) and the disks experienced a change of fracture mechanisms: now the facet-type-pattern fracture morphology dominated born by transgranular slip. This just was Zone II, revealed by the fracture of the broken disks. In all the other examined fractures the crack did not reach its critical depth of $1.3 \mathrm{~mm}$, i.e., transition to Zone II of crack growth did not occur.
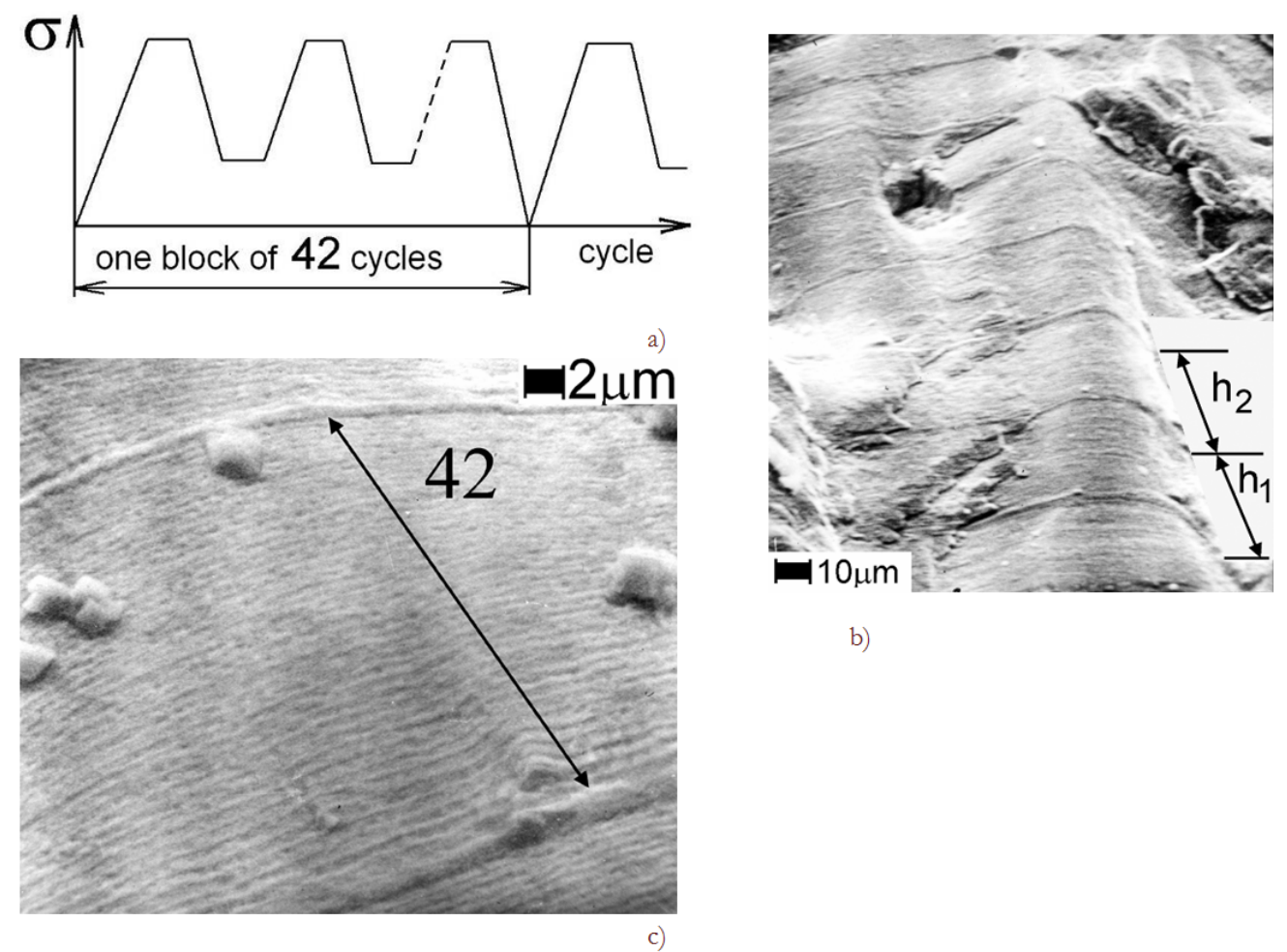

b)

Figure 8: (a) Block of loading waveform (schematic) of a Stage III turbine disk applied when bench-testing an NK8-2u engine and (b, c) fatigue-striation blocks, $h_{i}$, illustrating the fracture response of the disk loaded in the engine. 


\section{Crack growth in tested disks}

The tests of the disk P-3 were done according to a special routine by imitating blocks of 42 one-flight loading cycles, each block ended with a complete cutoff of the engine. The greatest and least numbers of engine revolutions corresponded to the end of take-off and reduced-speed regimes, respectively. On the tests, we opened the cracks to examine their growth behavior fractographically and have found 42 fatigue striations to be formed by 42 one-flight loading cycles (one test block, Fig. 8). The blocks of 42 striations, with the striation spacing nearly the same over a block area, were separated by a step (or a line) from one another. Each step formed to mark a complete cutoff of the engine. These findings confirmed that, in Zone I of crack growth (within 1.3-mm crack depth), each fatigue striation is indicative of a crack increment caused by a start-and-shut-down cycle of the engine, i.e., by a single flight of the aircraft.

We analyzed the crack-growth trends in the P-4 disk tested by ECP loading in the engine to discover that the disk-fracture morphology differed significantly from that peculiar the real in-service conditions. In the tests, the crack in Zone I was grown to 8-mm depth, Fig. 9; at this depth, the value of fatigue-striation spacing achieved nearly $2 \mu \mathrm{m}$. This is significantly greater than the critical value typical of changing for Zone II for in-service fractures. And, compared with the latter, striation spacing grew significantly faster with the crack depth.

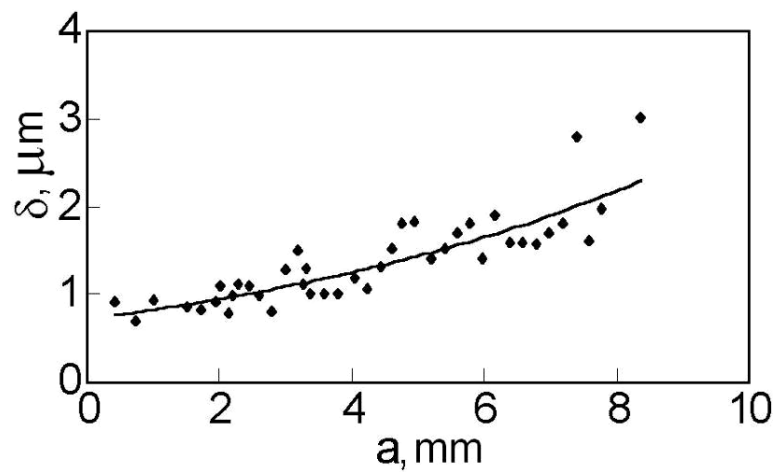

Figure 9: Striation spacing value $\delta$ against the minor axis, $a$, of semi-elliptically crack appeared in the turbine disk bench-tested by equivalent cyclic loading in an NK8-2u engine.

\section{DISCUSSION}

he number of loading cycles calculated from the number of fatigue striations showed agreement with the inservice operating time, Tab. 2. A larger operating time gave a greater number of fatigue striations. Hence, expecting fatigue striations to form during a start-and-shut-down cycle of the engine, a number of the fatigue striations must be characteristic of the growth period of a fatigue crack, measured as the number of flights of an aircraft.

\begin{tabular}{lcccccccc}
\hline Disk No. & $1^{*}$ & $2^{*}$ & 3 & 4 & $5^{*}$ & $6^{*}$ & 7 & 8 \\
$N_{f}$ (flights) & 1329 & 1335 & 1421 & 1499 & 1690 & 2041 & 2600 & 3121 \\
$N_{p}$ striations & 180 & 620 & 1000 & 860 & 760 & 710 & 1500 & 1360 \\
\hline
\end{tabular}

Table 2: Operating times $N_{f}$ of the disks since new and a calculated number $N_{p}$ of fatigue striations for the cracks detected in service (*In disks-No 1, 2, and 5, 6 cracks did not reach their critical depth).

The data on crack-growth period show significant scatter, which should be related to a difference in stress levels between the disk-hole sites. For instance, only one crack was detected in No. 4 disc, its depth, though, as large as $2.0 \mathrm{~mm}$. Yet other disks, of different operating time, exhibited four to twelve cracked holes. The holes may differ in the distance from the butt-end of the hub to the fracture origin site $(1.5$ to $13 \mathrm{~mm})$, which also confirms the case of difference in the stress level between the disk holes.

Having analyzed the growth trends of fatigue cracks in the disks made it possible to estimate the stressing extent and, based on an acquired relationship between the numbers of fatigue striations and start-and-shut-down cycles of the engine, establish the due inspection frequency of the disks. By calculations, the number of fatigue striations was found to never 
exceed the number of flights of an aircraft and, in some discs, respond to over $50 \%$ operating time (assuming one striation formed by one start-and-shut-down cycle of the engine (see Tab. 2).

Validity of using the above-mentioned relationship was evaluated based on the test results obtained for P-3 disk installed in an engine (see Fig.8). Having quantitatively estimated the fractographic parameters of fatigue fracture of turbine disks bench tested by ECP loading in an engine, we established that a single fatigue striation with a respective crack increment formed per each one-flight cycle under the takeoff conditions.

The stresses applied to the disk during ECP were significantly lower in such a bench test regime than in service. Using the fracture-mechanics approach, we compared the stressed states of the disks in the bench tests and in service.

For the discussed case of semi-elliptic crack a well-known formula of $K_{e}$ equivalent stress-intensity factor is applicable [17]:

$$
K_{e}=\left(\sigma_{e} \sqrt{\pi a}\right) /[\Phi(c / a)]
$$

In Eq.2, $\Phi(c / a)$ is the elliptic integral of the secondary type, whose value depends on the ratio $(c / a)$ of semi-elliptic-crack axes in any crack-growth direction.

In our case, term "equivalent" means that fractographic estimation of stresses based on fatigue striations value related to material reaction on its complicated stress-state. This reaction is equivalent in stress level with opened propagated crack by Mode I.

The Eq.2 can be applied correctly to the crack starting from a distance of $1 \mathrm{~mm}$ or greater from the in-hole surface of the disk: at that distance, effect of the surface-stress concentration is negligibly for crack-growth over the length in $1 \mathrm{~mm}$. However, the calculated equivalent stress is totally expressive of all the strengthening-and-weakening effects of prominent plastic deformation typical of even the very first loading cycle of low-cycle fatigue. We should stress on that the cracks to be in-service detected belong to a small kind as concerns a crack length (within $1 \mathrm{~mm}$ ) and the growth behavior of fatiguestriation spacing (linearly dependent of the crack length). For such cracks, using the concepts of strain-range or J-integral would be of greater accuracy and meaning than the concept of stress because of well-developed plastic deformation.

Nevertheless, when estimating a relationship between the characteristics of material behavior in service and in bench tests, the concept of equivalent stress remains still proper. Indeed, irrelevant to the way of loading, a value of striation spacing always corresponds to just a respective unique value of stress-intensity factor, completely determined by a respective equivalent stress $[4,6]$.

The disk material exhibits maximum stress intensity factor $\left(K_{e}\right)_{\max }=70 \mathrm{MPa} \mathrm{m}^{1 / 2}$ at the moment that the growth behavior of a fatigue crack changes from steady to unsteady, the value of fatigue-striation spacing being close to $1.2 \mu \mathrm{m}$. One can see that both from the Paris' curve in term of crack growth rate and fracture morphology of the material. We calculated elliptic integrals for the boundaries between Zone-I and Zone-II fractures of the broken P-1 and P-2 disks and for the line of $1.2 \mu \mathrm{m}$ striation spacing in one of the opened cracks which were also discovered in P-1 disk; the integrals appeared 1.0158, 1.0325, and 1.09, respectively. With the cracks dimensions and the respective above-calculated values substituted to Eq.1, we calculated $\sigma_{e}$ as 1130,1320 , and $1180 \mathrm{MPa}$. The calculations could be done owing to fractographic examination of those broken disks and artificially opened fatigue crack. Thus estimated equivalent stresses approximate to those acquired from the finite-element analysis of a complex stressed state of a disk with the shear stresses taken into account [11]. The above stress figures appear to exceed more than twice the stress level commonly acceptable for the disks. Accordingly, the disks bolted to the shaft through the holes in this particular way must be of a low expected durability.

We compared how much the disks were loaded in the bench-tests and in service. In so doing, we assumed that the stressintensity factors are the same for the same values of fatigue-striation spacing irrespective of the loading prehistory of the disks because there were not discovered difference in material properties for all investigated disks. The stress- and strainintensity factors were both discussed as representative of a stress pattern whether in bench-tests or service. From a comparative analysis, one can have a characteristic indicating how much the disks were stressed relative to one another. Hence, we can write,

$$
\left(K_{e}\right)_{0}=\left(K_{e}\right)_{t} \text { for } \delta=1.2 \mathrm{~mm}
$$

or

$$
\left(\sigma_{e}\right)_{0} /\left(\sigma_{e}\right)_{t}=\left(a_{t} / a_{0}\right)^{1 / 2} /\left(\Phi_{0} / \Phi_{t}\right)
$$


Here, in Eqs.3 and 4, subscripts " 0 " and " $\mathrm{t}$ " indicate to the cracking conditions in service and bench-tests, respectively. In the bench-tested disk, the $1.2 \mu \mathrm{m}$ spacing of fatigue striations corresponded to the crack depth and width of 3.5 and $8.0 \mathrm{~mm}$, respectively, which was significantly greater than in the in-service disks. For this crack geometry, 1.19 is the value of elliptic integral. With the crack-geometry parameters substituted in equation (3), we have

$$
\left(\sigma_{e}\right)_{0} /\left(\sigma_{e}\right)_{t}=(3.5 / 1.2)^{1 / 2} /(1.016 / 1.19)=1.46
$$

According to our calculations, the bench tests in an engine stress the disk to a level nearly as low as 0.75 of the level typical of real service. Assume that the disk durability reduces exponentially with increasing stress level for the exponent greater than two. In such a case, using the bench-test data in the durability simulation, we twice as much overestimates the expected operating time of the disk in service.

The above calculations all related to the early fracture zone, in which fatigue striations formed. Moreover, one can see from the formation pattern of fatigue striations that the in-service loading of the disk occurred under constant-strainamplitude conditions. This was also evident from the finding that unsteady crack growth covered quite a long distance. Zones II and III of crack growth occupy significant portions of this area. The above data indicated that the stress level of the disk should be substantially reduced.

To establish the greatest tolerable period of disc service between two sequential inspections (solve the question of inspection frequency), we should have estimated the growth period of a crack throughout these two zones. We did such an estimation based on the knowledge of the laws of fatigue cracking. In so doing, we assumed that

$\checkmark$ the crack growth accelerated steadily throughout Zone II of the fracture as long as it was controlled by a constant strain amplitude (like in Zone I of the fracture) and

$\checkmark$ the distance between two nearest boundaries, separating two regions of different oxidation tints and marking the crack-tip positions, corresponds to a crack increment during one flight: indeed, not less than five typical tints changed regularly in Zone III of the disk-web fracture.

Within a distance 20-mm in depth from the hole-bolt-surface (Zone-II), fracture immediately adjacent to the central hole (to pass the engine shaft) of the disk. The greatest interboundary distance approximated $1.5 \mathrm{~mm}$ for a single-tint region. With the above assumptions, crack-growth rate measured within a one-flight 1.2-mm crack path, and a relationship obtained earlier [4], the estimation looked as

$$
N_{p 2}=\lg \left(1.5 / 1.2 \times 10^{-3}\right) / \lg (1+1.5 / 18.8)=110 \text { cycles }
$$

Thus calculated a figure indicates that the crack might grow for less than 1000 flights in any of the above fracture zones (mind the Tab. 2 data). The crack-growth period may exceed 50\% total durability of a part under the low-cycle fatigue conditions. Hence, according to the above calculations, we should expect fatigue cracks to appear in many disks that passed more than 2000 flights. Besides, quite a number of those cracks should have shown dimensions beyond the steadygrowth limit. To confirm this view, we inspected once all the disks that passed more than 2700 flights. We did it insitu with the eddy-current method, the rear bearing of the disk removed.

Of those disks, $40 \%$ turned out to reveal fatigue cracks. The applied method is low sensitive compared with, e.g., a dyepenetrate one. In addition, accessing into the holes was difficult. Therefore, we could be quite certain that the real portion of the discs with service-induced cracks (including small ones) is significantly greater. Based on this once-only inspection, a limiting operating time of 2700 flights was introduced into practice.

Accordingly, the disk design was modified as concerned the way of fastening a disk to the engine shaft. With the new design, stress concentration was reduced to result in a nearly thirty-fold increased durability of the disk. The discs that passed more than 2700 flights were first to be replaced by the newly designed disks.

The replacement activity of the old- by new-type discs required time. Hence, the service safety was to be ensured with the old-type disks still in service. While the new-type disks were being gradually put in use instead of the old ones, the problem was temporarily solved with the damage-tolerance approach applied. In so doing, a recurrent inspection of the disks by the eddy-current method was put into practice to examine the area between the hub and web as frequent as

$\checkmark$ after each 50 flights for the operating time not longer than 2000 to 2400 flights;

$\checkmark$ after 20 flights for the operating time of 2400 to 2500 flights;

$\checkmark$ after four (plus two) flights for the operating time of 2500 to 2600 flights; and

$\checkmark$ after two (plus two) flights for the operating time of 2600 to 2700 flights.

These periodicities were recommended based on the fractographic data and because the desired inspecting area of a disk (crosspieces between the holes for a bolt and for the engine shaft) was difficult to access in the discussed structure. With the rare disk-bearing structure not moved, the fillet area between the disk hub and web was only accessible for inspecting. 
In the web, a crack-growth period did not exceed five flights. Yet it achieved 110 flights in the above-mentioned crosspieces. Assuming a once overseen crack likely, the above-mentioned inspection frequencies were introduced.

The recommended inspection sequence was introduced up to the disk-shaft joint has been redesigned. The disk to shaft joining was organized by the inner diameter of the discussed disk hub. The reconstructed disk joint to shaft has shown airworthiness for aircrafts with this type of engine without fatigue in-service disks cracking in recommended design service goal.

\section{CONCLUSION}

1. In-service turbine disks fatigue cracking of EI437B superalloy in aero-engine NK8-2u of the III stage was considered and LCF regime of their failure was demonstrated.

2. Unified description of fatigue crack growth in metals was applied to stress equivalent $\sigma_{e}$ value estimation based on fatigue striations measurement in fracture surfaces. It was shown that in-service stress $\sigma_{e}$-level is very high that directed to earlier crack origination by the disk hole-surfaces in bolt-joint than it was designed.

3. Crack growth period for in-service cracked disks was estimated based on fatigue striation spacing measurements. It was discovered one-to-one relation between fatigue striation spacing and crack increment in one flight.

4. Based on crack growth period estimation results, it was recommended in-service non-destructive disks inspection with different intervals in dependence of operating time in service at the moment of developed tests.

\section{REFERENCE}

[1] Fractography in Failure Analysis. ASTM STP 645, ASTM, Philadelphia, (1978).

[2] Failure Analysis and Prevention: Metals Handbook, ASM. Handbook Commit., U.S., 11 (1986).

[3] L. Varkoly, J. Zuidema, B. Varkolyova, M. Chalupova, Fatigue failures of materials. TU Delf, Netherlands, (1998) 235.

[4] A. A. Shanyavskiy, Tolerance in-service fatigue cracking of aircraft structures. Synergetics in engineering applications. Ufa, Russia, (2003).

[5] A. A. Shanyavskiy, In: PROBAMAT- 21st Century: Probabilities and Materials, Ed. K. Franzisconys, Kluwer Academic Publisher, Netherlands, (1998) 11.

[6] A. A. Shanyavskiy, In: New results in fatigue and fracture, Eds: W. Kasprzak, E. Macha, V. Panasyuk, M.K. Schaper, Mechanika, Opole-Zakopane, Poland; 1 (300) (2005) 277.

[7] A. A. Shanyavskiy, Procedia Engineering, 2(1) (2010) 241.

[8] A. Carpinteri, A. Spagnoli, S. Vantadori, Fatigue Fract Engng Mater Struct, 26 (2003) 515.

[9] A. A. Shanyavskiy, Fatigue Fract Engng Mater Struct, 19 (1996) 1445.

[10] I. V. Demyanushko, I. A. Birger, Mashinostroenie, Moscow, Russia, (1978).

[11] I. V. Demyanushko, Yu. M. Temes, Problems of Strength, 4 (1981) 49.

[12] A. A. Shanyavskiy, A. I. Losev, M. D. Banov, Fatigue Fract. Engng Mater. Struct., 18 (1998) 539.

[13] V. I. Astafiev, D. G. Fedorchenko, L. N. Tzypkaikin, In: Sixth Intern. Fatigue Conf., Fatigue'96, Berlin, 6-10 May, 1 (1996) 499.

[14] V. I. Zeitlin, D. G. Fedorchenko, Problems of Strength, 2 (1983) 13.

[15] G.J. Lloyd, Fatigue at High temperature, Applied Science Publishers, London, New York, (1983) 187.

[16] Y. Murakami, In: Low Cycle Fatigue, Eds. H. D. Solomon, G. R. Halford, L. R. Kaisand, P. Leis, ASTM STP 942, ASTM, Philadelphia, (1986) 1048.

[17] Y. Murakami (Ed.) Stress Intensity Factors Handbook, Pergamon Press, Oxford (1987).

\section{NOMENCLATURE}

a minor semi-axis of elliptical fatigue crack

c major semi-axis of elliptical fatigue crack

$\mathrm{da} / \mathrm{dN}$ crack-growth rate in the depth direction

$\mathrm{dc} / \mathrm{dN}$ fatigue-crack-growth rate at the specimen surface

$\mathrm{K}_{\mathrm{I}} \quad$ Mode I stress intensity factor 
$\mathrm{K}_{\max } \quad$ maximum Mode I stress intensity factor

$\left(\mathrm{K}_{\max }\right)_{\mathrm{h}}$ threshold value of stress-intensity factor to start of hold-time influencing fatigue cracking

$\mathrm{K}_{\mathrm{e}} \quad$ equivalent Mode I stress intensity factor

$\left(\mathrm{K}_{\mathrm{e}}\right)_{\max }$ maximum value of $K_{e}$ for steady crack growth

$\Delta \mathrm{K}_{\text {eff }} \quad$ effective stress intensity factor in Mode I crack opening

$\mathrm{N}_{\mathrm{f}} \quad$ lifetime to failure (durability)

$\mathrm{N}_{\mathrm{p}} \quad$ fatigue crack growth period

$\Delta \mathrm{q}_{\mathrm{i}} \quad$ range of stress in bifurcation $\mathrm{i}$-area

$\mathrm{R}$ stress ratio

$\delta \quad$ fatigue striation spacing

$\lambda$ biaxial stress ratio $\left(\sigma_{1} / \sigma_{2}\right)$

$\sigma_{0.2} \quad 0.2 \%$ offset yield strength

$\sigma_{1} \quad$ tensile stress opening fatigue crack

$\sigma_{2} \quad$ tensile or compressive stress acting in a direction perpendicular to the $\sigma_{1}$-direction

$\sigma_{w i} \quad$ mean stress for bifurcation i-area

$\sigma_{u} \quad$ Ultimate tensile stress 